Agence de Coopération Culturelle et Technique

UNESCO

The British Academy

Leuven University Press

The Government of Senegal

The Government of Kenya

Longman (Nigeria)

U.A.C. International

The Inchcape Charitable Trust

Low \& Bonar Group Ltd.

\title{
The former Library of the I.A.I. at Manchester University
}

The former Library of the I.A.I. is now housed in the Social Science Wing of the John Rylands University Library of Manchester, which bought the bulk of it in the early 1970s. The collection consists of c. 2,500 books, about 100 incomplete runs of periodicals (as well as some complete ones and some single issues) and over 3,000 pamphlets and censuses.

The collection is arranged in the same classified order as its items in the classified catalogue of the I.A.I. Since other "africana" in the library are classified by Dewey, continuations and new items have been added into the Main Library Collection. This, however, is no hindrance to users, whò can consult both catalogues.

The I.A.I. collection is accessible to anyone through interlibrary loan, to members of the I.A.I. through direct loan, and to all staff and postgraduate students of our university through "limited access". It means, in practice, that material is brought to the user, unless the user requests browsing. Undergraduates can use the collection if they are recommended by their teachers.

\section{Centre for African Family Studies (CAFS), Nairobi}

CAFS is an institution of the International Planned Parenthood Federation based in Nairobi, Kenya, providing short but intensive training courses in population, family planning and family life education aimed at integrating these activities into socioeconomic development programmes in sub-Saharan Africa.

Over the years there has been increasing recognition of the relationship between population and family planning policies and the progress of socioeconomic development, culminating during the World Population Conference (Bucharest, 1974) in a call for the integration of family planning and family life education into broader development strategies.

Other key international meetings such as the World Food Conference (Rome, 1974), the International Women's Conference (Mexico, 1975), and the IPPF Conference on Family Welfare and Development in Africa (Nigeria, 1976) have also stressed the importance of family planning as an integral part of efforts to maximize food resources, upgrade the status of women and improve the quality of family life.

Despite increasing recognition on the part of many African governments of the need to incorporate family planning in a broad range of health, community and extension services, the necessary conditions for such integration do not always exist. A major constraint is the lack of trained manpower among development personnel with the 